\title{
GEOPROCESSAMENTO APLICADO A GESTÃO TERRITORIAL URBANA DE PEDRO VELHO/RN
}

\author{
L. A. M. B. CORREIA ${ }^{1}$, M. L. M. GALVÃO ${ }^{{ }^{*}}$ e A. L. C. ARAÚJO ${ }^{2}$ \\ ${ }^{1}$ Universidade Federal do Rio Grande do Norte \\ ${ }^{2}$ Instituto Federal de Educação, Ciência e Tecnologia do Rio Grande do Norte \\ luiza.galvao@ifrn.edu.br*
}

Artigo submetido em dezembro/2014 e aceito em dezembro/2014

DOI: $10.15628 /$ geoconexoes.2015.2648

\section{RESUMO}

Consta no trabalho breve discussão acerca do uso do geoprocessamento aplicado à gestão do território, particularizado como estudo de caso a Lagoa de Estabilização localizada na cidade de Pedro Velho (Rio Grande do Norte/ Brasil). Apresenta uma síntese dos resultados, quanto à condição da lagoa da cidade, identificados pelo projeto "O uso de geoprocessamento aplicado à gestão de lagoas de estabilização no Rio Grande do Norte (Brasil)" no ano de 2010. Tais resultados indicam contradição técnica, quanto à eficiência do sistema de tratamento de esgoto, uma vez que ao diferenciar as amostras que atestam a adequabilidade da água em bruta e filtrada, verifica-se que estão em desacordo o que estabelece a resolução do Conselho Nacional de Meio Ambiente (CONAMA), para operação das lagoas. A discussão apresentada está embasada nos conceitos de Geoprocessamento - Silva (2007), Camargo (1997), Polidoro \& Barros (2010), Fitz (2008); Planejamento e Gestão Territorial - Clementino (2008), Carlos (2007); e Território - Santos (1994); contemplando ainda breves considerações acerca das Lagoas de Estabilização em Andrade (2006) e Araújo (et al, 2011).

PALAVRAS-CHAVE: Geoprocessamento, Gestão do Território, Lagoa de Estabilização, Pedro Velho/RN (Brasil).

\section{GEOPROCESSING APPLIED TO THE URBAN TERRITORIAL MANAGEMENT OF PEDRO VELHO/RN}

\begin{abstract}
This paper presents a brief discussion about the use of GIS applied to land management, particularized as a case study: the Stabilization Pond in the town of Pedro Velho (Rio Grande do Norte / Brazil). A summary of the results regarding the condition of the city lagoon, identified by the project "The use of Geoprocessing applied to the management of waste stabilization ponds in Rio Grande do Norte (Brazil)", in 2011, is also part of this work. These results indicate a technical contradiction, as regards the efficiency of the sewage treatment, since the difference samples which attest to
\end{abstract}

the suitability of the water in raw and filtered water show a variance with the established resolution of the National Council of the Environment (CONAMA) regarding the operation of lagoons. Underlie this discussion the concepts of GIS - Silva (2007), Camargo (1997), Polidoro \& Barros (2010), Fitz (2008); Planning and Territorial Management - Clementino (2008), Carlos (2007); and Territory - Santos (1994); and still considering brief remarks about Stabilization Ponds in Andrade (2006) and Araújo (et al, 2011).

KEYWORDS: Use until five (05) keywords by separating them with commas. 


\section{INTRODUÇÃO}

Os gestores municipais podem encontrar nas geotecnologias subsídios para elaboração do planejamento territorial dos espaços rural e urbano. Contudo há de se considerar a necessidade do município reunir condições técnicas e culturais para implantação do geoprocessamento, o qual propicia a coleta e o processamento de dados informatizados sobre a sua geografia. As informações obtidas tornam-se instrumentos para planejar soluções espaciais que vão do diagnóstico do problema à tomada de decisão.

Assim, o geoprocessamento apresenta-se como mediador e facilitador na análise dos produtos cartográficos, pois integra o volume de dados espaciais provenientes de diferentes fontes (POLIDORO \& BARROS, 2010). Torna os resultados de rápida visualização e fácil entendimento para definição do uso do território, aqui compreendido como sinônimo de espaço geográfico e instância social (SANTOS, 1994).

O espaço geográfico, objeto de análise aqui apresentado corresponde a Lagoa de Estabilização localizada na cidade de Pedro Velho/Rio Grande do Norte (Brasil). A referida lagoa integrou o projeto desenvolvido pelo IFRN ${ }^{1}$ em parceria com a FUNASA ${ }^{2}$, denominado "O uso de geoprocessamento aplicado à gestão de lagoas de estabilização no Rio Grande do Norte" e, apresenta uma dinâmica singular, problematizada ao longo deste trabalho.

O processo de construção do artigo em tela contempla revisão bibliográfica, visita técnica à cidade de Pedro Velho/RN com registro fotográfico e georreferenciamento das localidades visitadas, e ainda o geoprocessamento dos dados obtidos por meio da visita e das atividades desenvolvidas ao longo do projeto supracitado.

Os conceitos norteadores da discussão aqui apresentada são: Geoprocessamento, Território, Planejamento e Gestão Territorial; e estão embasados, respectivamente, em Silva (2007), Camargo (1997), Polidoro \& Barros (2010), Fitz (2008), Santos (1994), Clementino (2008), e Carlos (2007). Também contempla breves considerações acerca das Lagoas de Estabilização em Andrade (2006) e Araújo (et al, 2011). O trabalho está dividido em seções, sendo a primeira a Introdução, seguida de Considerações iniciais, Resultados e Discursões e, das Considerações Finais.

\section{CONSIDERAÇÕES INCIAIS}

A Lagoa de estabilização aqui problematizada é localizada na cidade de Pedro Velho/RN (Figura 01), distante 78 quilômetros da capital do estado. Este município contabiliza um total de 14.114 habitantes, distribuídos em 7.248 na zona urbana e 6.866 na zona rural (IBGE, 2010); e apresentou, em 2010, índice de desenvolvimento humano de 0,568, ocupando assim a 126ạ posição no RN (ATLAS DE DESENVOL VIMENTO HUMANO NO BRASIL, 2013). Com pouco mais de $193 \mathrm{~km}^{2}$ de extensão a cidade se destaca, também, por não possuir todo o território urbano

\footnotetext{
${ }^{1}$ Instituto Federal de Educação, Ciência e Tecnologia do Rio Grande do Norte. Campus Natal Central.

${ }^{2}$ Fundação Nacional de Saúde, instituição vinculada ao Ministério da Saúde.
} 
saneado mesmo dispondo de duas lagoas de tratamento de esgotos: uma de responsabilidade do município e outra gerida pela CAERN ${ }^{3}$.

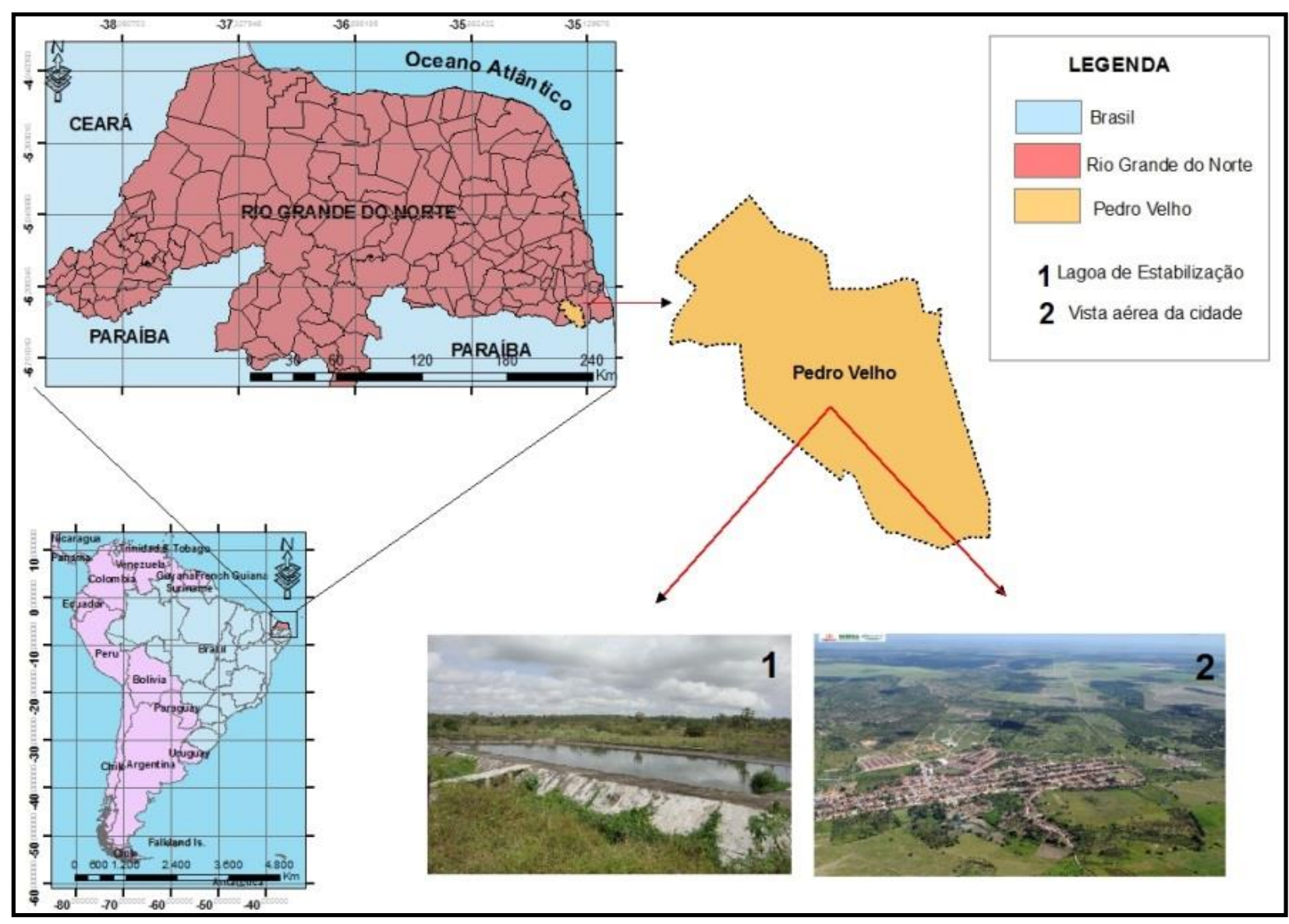

Figura 01: Localização da Cidade de Pedro Velho/RN (Brasil)

Considerando a cidade como um espaço dinâmico, de contínuas mudanças, o geoprocessamento enquanto tecnologia, associado aos Sistemas de Informações Geográficas (SIG's), oferecem subsídios cruciais a tomada de decisão dos gestores em todas as esferas. Não sendo diferente para a cidade de Pedro Velho/RN onde o recorte espacial problematizado está localizado. Ressalta-se, contudo, que a construção de um SIG e o geoprocessamento das informações para tomada de decisão deve ser encabeçada por um conjunto de profissionais que possam contribuir com os métodos de análise de suas respectivas áreas de atuação, tornando, teoricamente, a decisão final mais consistente e precisa.

Definido como um "conjunto de técnicas computacionais, o geoprocessamento opera sobre bases de dados, transformando-os em informação relevante" (SILVA, 2007). De posse das informações e realizadas as análises, os resultados se tornam muito úteis no planejamento territorial, uma vez que ele se torna a "forma estruturada de tomar decisões para o desenvolvimento da cidade" (CLEMENTINO, 2008). Contudo, a passagem dos dados do mundo real para o mundo virtual deverá ocorrer "a partir da utilização de modelos, os quais deverão seguir padrões conceituais vinculados à maneira como o individuo concebe o espaço observado" (FITZ, 2008).

\footnotetext{
${ }^{3}$ CAERN - Companhia de Águas e Esgotos do Rio Grande do Norte, empresa responsável pelo abastecimento de água e tratamento dos esgotos na maioria dos municípios potiguares.
} 
Concebendo a Lagoa de estabilização como "Sistema de tratamento biológico em que a estabilização da matéria orgânica é realizada pela oxidação bacteriológica (oxidação aeróbia ou fermentação anaeróbia) e/ou redução fotossintética das algas" (ANDRADE, 2006); o trabalho defende que a aplicação de técnicas de geoprocessamento em sistemas de tratamento de esgotos permite uma maior eficácia na execução de planos de operação e manutenção desses sistemas; reconhecendo assim a relevância do georreferenciamento para a gestão do território e, problematizando os resultados apresentados pelos órgãos oficiais quanto à eficiência desse sistema em Pedro Velho/RN.

\section{RESULTADOS E DISCUSSÕES}

As Lagoas de Estabilização são classificadas, de acordo com a forma predominante pela qual se dá à estabilização da matéria orgânica, em: anaeróbicas, facultativas, aeróbicas, aeradas e de maturação. Em Pedro Velho/RN, o sistema de tratamento por lagoa de estabilização, avaliada com frequência mensal ao longo de um ano (2010), é composto por: tratamento preliminar, estação elevatória, caixa de distribuição, lagoa facultativa primária e duas lagoas de maturação (Figura 02).

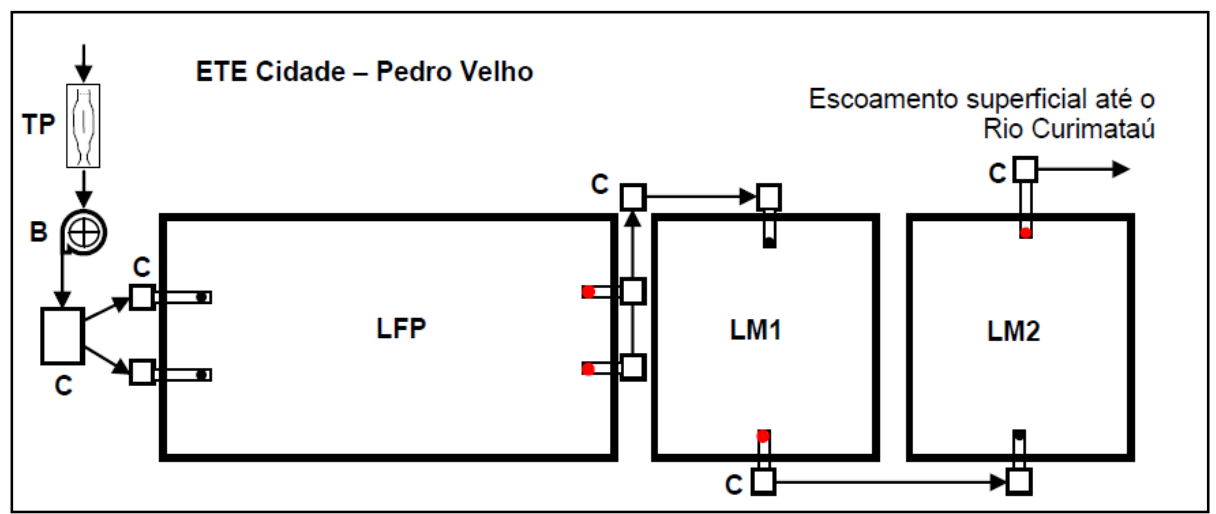

\section{LEGENDA}

TP - tratamento preliminar $B$ - estação elevatória C - caixa de distribuição LFP - lagoa facultativa LM - lagoa de maturação NA - nível de d'água - ponto de entrada do afluente - ponto de saída do efluente

Figura 02- Esquema de disposição das lagoas que compõem a estação de tratamento de esgotos da cidade de Pedro Velho - RN

Fonte: Araújo et al (2011)

A análise global dos resultados, embora aponte a redução de $84 \%$ na demanda bioquímica de oxigênio $(\mathrm{DBO})^{4}$ da região administrativa a qual pertence a Lagoa (Região Litoral $\mathrm{Sul}^{5}$ ), revela também as contradições que permeiam os parâmetros legais de gestão desta tecnologia.

A realidade nacional de flexibilização legal quanto às orientações para qualidade do efluente final das lagoas de estabilização, a exemplo da Resolução Conama 430/ 2011 - que dispõe sobre as condições e padrões de lançamento de efluentes - põem em situação de vulnerabilidade ambiental a população do entorno dessas lagoas ao diferenciar as amostras que atestam a adequabilidade do sistema em bruta e filtrada. A diferenciação dessas amostras permite que algumas lagoas continuem em operação mesmo diante dos riscos que oferecem a segurança e a saúde da população.

\footnotetext{
${ }^{4}$ Corresponde à quantidade de oxigênio utilizada pelos microorganismos na degradação bioquímica de matéria orgânica, sendo utilizado como parâmetro de poluição.

${ }^{5}$ Uma das sete regiões administrativas da Companhia de Águas e Esgotos do Rio Grande do Norte - CAERN
} 
No caso de Pedro Velho, na avaliação da temperatura, do pH e da DBO, o sistema apresentou adequabilidade somente nas duas primeiras variáveis, uma vez que, segundo os padrões estabelecidos pela Resolução supracitada (valores menores ou igual a $120 \mathrm{mg} / \mathrm{L}$ ) a lagoa atenderia o padrão de lançamento de DBO apenas para o efluente filtrado, com $100 \mathrm{mg} / \mathrm{L}$, pois para o efluente bruto a concentração verificada foi de $178 \mathrm{mg} / \mathrm{L}$ (48\% acima do valor limite).

Soma-se ao panorama de contradição técnica, o pouco compromisso dos gestores municipais de Pedro Velho/RN em realizar o tratamento dinâmico e contínuo requerido pela lagoa e determinado pela Secretaria Nacional de Saneamento Ambiental do Ministério das Cidades, cabendo à gestão municipal "assegurar à população os direitos humanos fundamentais de acesso à água potável em qualidade e quantidade suficientes, e a vida em ambiente salubre nas cidades e no campo" (BRASIL, 2013). Percebe-se que não é observada a realidade material sobre o qual o espaço é cotidianamente produzido, não se pensa o território - a partir da indissociável relação natureza e sociedade - enquanto prática socioespacial, mas reduzido enquanto quadro físico com um montante populacional. (CARLOS, 2007).

Assim, com base no que foi apresentado, pode-se afirmar que mesmo contando com a Lagoa de Estabilização a cidade não tem logrado êxito no seu papel de promover um ambiente salubre e condições dignas de vida à população. Isso ocorre na medida em que o tratamento final do esgoto não considera a proteção ao meio e a promoção da salubridade, ocorrendo de forma aleatória e não supervisionada, fato que contribui para diminuição da eficiência do sistema e, por conseguinte do próprio tratamento. Na ocasião da visita técnica observou-se ainda alto grau de poluição das cercanias da Lagoa e a precária estrutura física com sinais de desgastes, o que indicava a falta de acompanhamento e gestão daquele território (Figura 03)
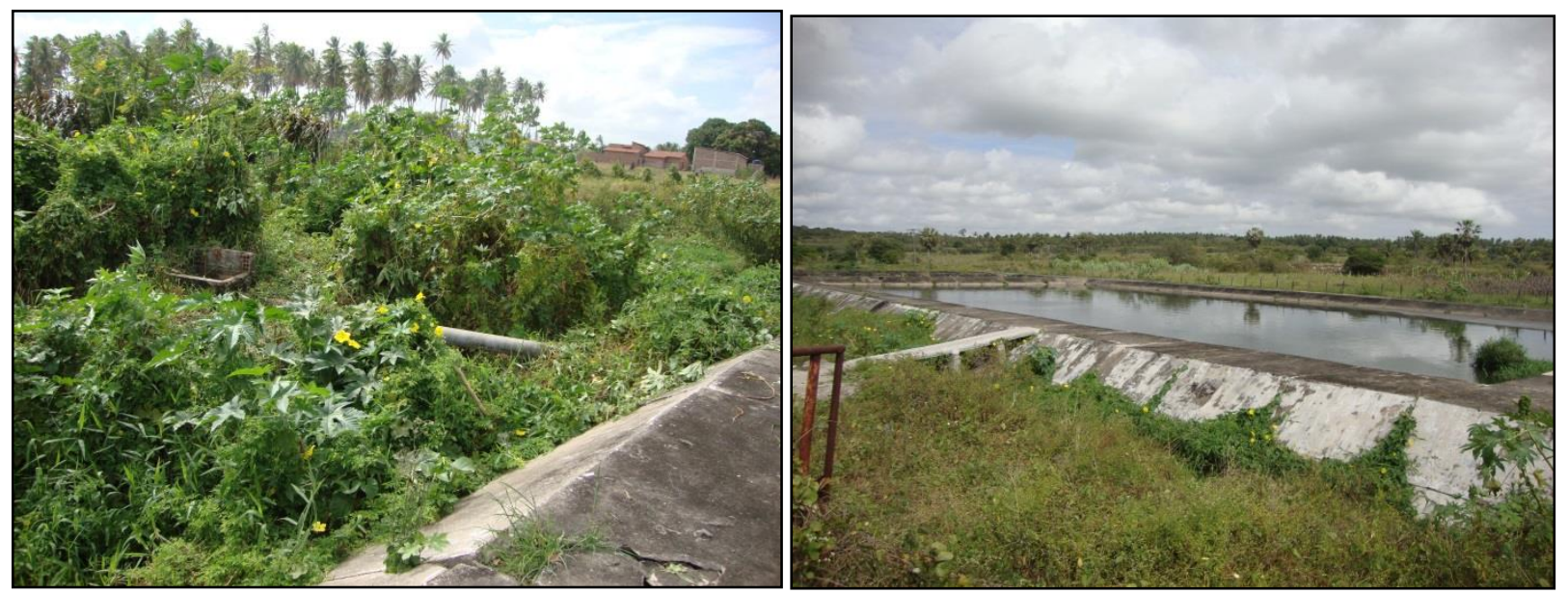

Figura 03 - Imagem do avanço do mato nas cercanias da lagoa e sinais de desgaste da sua estrutura. Fonte: acervo dos autores (2014).

Apesar desse aparente abandono a Lagoa de Estabilização do município de Pedro Velho/RN apresenta 85\% de eficiência na remoção da DBO (ARAÚJO ET AL, 2011). Atestando assim, as inúmeras vantagens das Lagoas de Estabilização frente a outras formas de tratamento de despejos sanitários, reforçando sua capacidade de suportar cargas orgânicas e hidráulicas elevadas, e de trabalhar com elevado potencial mesmo quando as condições mínimas são inexistentes.

É certo que o fato do sistema operar com expressivo êxito mesmo diante de situação de extremo abandono não justifica a postura negligente do município quanto a sua gestão - sendo 
ele o responsável legal pela promoção da cidade sustentável, direito de todo cidadão. A construção coletiva dessa cidade sustentável perpassa, também, pelo emprego das tecnologias para otimização dos serviços prestados a população e melhoramento do processo de gestão de nossas cidades, já que é nela onde os pleitos sociais se manifestam, anseios como acesso à água de qualidade, rede coletora de esgoto, saúde, educação, e moradia.

\section{CONSIDERAÇÕES FINAIS}

Sabe-se que a aplicação de técnicas de geoprocessamento em sistemas de tratamento de esgotos permite uma maior eficácia na execução de planos de operação e manutenção desses sistemas. Sendo assim, defende-se que uma alternativa para melhoramento das condições da Lagoa de Estabilização de Pedro Velho/RN, e, por conseguinte da qualidade de vida da população do seu entorno, seja o uso das geotecnologias para identificação das áreas afetadas e planejamento de ações mitigadoras, bem como o investimento na manutenção e operação da Lagoa. Concebendo o seu território em sua plenitude e fazendo uso do senso critico para operação dessas geotecnologias e análises dos seus resultados.

É notável que a difusão das técnicas se dá de maneira amplamente heterogênea, pois as mesmas apresentam-se no território, no tempo e no espaço de forma desigual (SANTOS, 1994). Com isso, ao definirmos a fase atual vivida pela sociedade, o chamado meio técnico - cientifico informacional, não basta apenas adicionar à noção de construção e/ou reconstrução do espaço a informação, em complementação à ciência e a técnica. É preciso compreender que o território se informatiza mais e mais rápido que a sociedade, uma vez que a sua transformação supõe o uso da informação que está presente também nos objetos (SANTOS, 1998).

Acredita-se, portanto que o uso do geoprocessamento enquanto tecnologia transdisciplinar aliados aos sistemas de informações geográficas (SIG/GIS), enquanto sistemas computacionais (FITZ, 2008), proporcionará aos técnicos municipais em Pedro Velho/RN a possibilidade de simular problemas, criar projetos, planejar ações e usar as informações geradas na busca de soluções para suas formulações. Para tanto, é preciso entender o território para agir sobre ele e, afastar o risco de alienação e de perda do sentido da existência individual e coletiva (SANTOS, 1994).

Entender o território da pequena cidade do nordeste brasileiro perpassa pela superação de mazelas crônicas como a tenra educação, o abandono, a fome, a pobreza e as insalubres condições de vida. Entender que a situação destes territórios, hoje inseridos - ainda que parcialmente - no processo de globalização, provém da ação crônica de uma minoria e não da "vontade de Deus" é o grande desafio de uma gestão publica participativa e da Geografia enquanto ciência critica que desvenda a relação sociedade - natureza.

Diante do exposto reafirmamos a importância de iniciativas como a do projeto de pesquisa "O uso de geoprocessamento aplicado a lagoas de estabilização", que propiciam a apropriação dos recursos tecnológicos - no caso aqui o geoprocessamento - para otimização da gestão do território das lagoas de estabilização no estado do Rio Grande do Norte. Tornando público, por meio de publicações científicas, os resultados obtidos na análise da qualidade e eficiência dos sistemas acompanhados, bem como os produtos cartográficos fruto do processamento desses dados. Reafirmamos ainda a necessidade, não só de apropriação destas 
tecnologias, mas de capacitação de pessoal para sua operação além da necessidade de se desenvolver uma cultura de uso das tecnologias para auxilio na tomada de decisões.

\section{REFERÊNCIAS}

1. ANDRADE, João Bosco de. Lagoas de Estabilização. In: ANDRADE; Notas de aula: Saneamento Básico - Sistemas de Esgotamento Sanitário (Capitulo VII). 2006. Disponível em: http://pt.scribd.com/doc/25764436/82/CAPITULO-VII-\%E2\%80\%93-LAGOAS-DEESTABILIZACAO. Acesso: Agosto/2012. (Brasil)

2. ARAUJO, André Calado de; ANDRADE NETO, Cícero Onofre de; OLIVEIRA, Flávio Gutenberg de; SANTOS, Jerônimo Pereira dos. MORAES, Douglisnilson Ferreira de; PIRES, Adriana Dias Moreira. Avaliação operacional e da eficiência de lagoas de estabilização no estado do RN. Relatório apresentado ao Programa de Pesquisa em Saúde e Saneamento. Ministério da Saúde - Fundação Nacional de Saúde (FUNASA), 2011. . (Brasil)

3. BRASIL. Ministério do Planejamento, Orçamento e Gestão. Secretaria de Gestão. Comissão Européia. Conceito de planejamento territorial. In: Textos de Referência em Planejamento Territorial Integrado. Brasília: MP, 2007. 90 p. (Brasil)

4. BRASIL. Ministério das Cidades. Secretaria Nacional de Saneamento Ambiental. Saneamento. Disponível em: http://www.cidades.gov.br/index.php?option=com_content\&view=section\& layout=blog\&id=6\&ltemid=110. Acesso: Janeiro/ 2013. (Brasil)

5. CARLOS, Ana Fani Alessandri. O Espaço Urbano: Novos Escritos sobre a Cidade. São Paulo: FFLCH, 2007, 123p. . (Brasil)

6. CAMARGO, M. U. C. Sistemas de Informações Geográficas como Instrumento de Gestão de Saneamento. Rio de Janeiro. ABES, 1997. 224p. (Brasil)

7. CLEMENTINO, Maria do Livramento. Ordenamento e planejamento territorial: a falta que faz o plano metropolitano. Disponível em: http://www.ub.edu/geocrit/-xcol/252.htm. Acesso: 22/01/2013. (Brasil)

8. FUNDAÇÃO GETULIO VARGAS. Trata Brasil: Saneamento e Saúde. Coordenador: Marcelo Cortês Neri. Rio de Janeiro: FGV/ IBRE, CPS, 2007. Disponível em: http://www.tratabrasil. org.br/ Acesso: Setembro/2012. (Brasil)

9. FITZ, Paulo Roberto. Geoprocessamento sem complicação. São Paulo: Oficina de Textos, 2008. (Brasil)

10. POLIDORO, Maurício. BARROS, Mirian Vizintim Fernandes. Utilização de geotecnologias no suporte a gestão de políticas públicas municipais. Revista Eletrônica da Associação dos Geógrafos Brasileiros - Seção Três Lagoas/MS - no 11 - Ano 7, Maio 2010. Disponivel em: http://www.uel.br/projetos/atlasrml/publicacoes/periodicos/4.pdf. Acesso: 22/01/2013. . (Brasil)

11. SANTOS, Milton. Técnica, espaço, tempo. São Paulo: Editora Hucitec, 1994

12. SILVA, J.X. da; ZAIDAN, R.T. (Org.) Geoprocessamento e Análise Ambiental: aplicações. $2^{\mathrm{a}}$ ed. Rio de Janeiro: Bertrand Brasil, 2007. (Brasil)

13. SILVA FILHO, Pedro Alves. Diagnostico Operacional de Lagoas de Estabilização. 2007. 169f. Dissertação (Mestrado em Engenharia Sanitária) - Universidade Federal do Rio Grande do Norte. Centro de Tecnologia. Programa Regional de Pós- Graduação em Engenharia Sanitária, 2007. . (Brasil) 